\title{
Political Epistemology, Experts and the Aggregation of Knowledge
}

\author{
Stephen Turner*
}

Begin with a bit of political theory, in this case the emblematic passage in the most consequential political theory text of the twentieth century, Carl Schmitt's Concept of the Political:

Words such as state, republic, society, class, as well as sovereignty, constitutional state, absolutism, dictatorship, economic planning, neutral or total state, and so on, are incomprehensible if one does not know exactly who is affected, combated, refuted, or negated by such terms (1976, 30-31).

What does this have to do with expertise? Plenty. Expert claims routinely "affect, combat, refute, and negate" someone or some faction or grouping of persons. When scientists proclaim the truth of Darwinism, they refute, negate, and whatnot the Christian view of the creation, and thus Christians. When research is done on racial differences, it affects, negates, and so on, those who are negatively characterized. This is why Phillip Kitcher argues that it should be banned $(2001,95)$. Some truths are too dangerous to ever inquire into, because, he reasons, even by inquiring we legitimate the negation that racial distinctions already carry. Expert claims also favour or disfavour policies or decisions which have factions or persons supporting them. When Robert Oppenheimer insisted on technical grounds that the $\mathrm{H}$ - Bomb was unfeasible, his opinion disfavoured, not to say negated and combated, the faction that supported the decision and favoured the position of Stalin (cf. Turner 2003). Claims about the human contribution to climate change favour the faction that believes in an extensive role of the state in regulating the economy. All these claims are "political."

But, one might ask, isn't it the case that there is a fact of the matter in these cases? And aren't facts themselves non-political? According to this definition of the political, the answer is no. As Schmitt's famous slogan puts it: what is

\footnotetext{
* Stephen Turner is Graduate Research Professor, Department of Philosophy, University of South Florida. His books have been on Weber and political theory, practice theory, liberal democracy and experts, the history of social science, and the history of methodology and statistics. Several of his papers on expertise are cited in this article. In addition, he has written on standard philosophical issues in the areas of action explanation, translation, and rationality, among other topics. He recently co-edited Philosophy of anthropology and sociology and The Sage handbook of social science methodology.
}

Spontaneous Generations 1:1 (2007). ISSN 1913-0465. University of Toronto 
political is a political question. Making something scientific, or true, doesn't mean making it non-political. The political/non-political distinction, as Schmitt goes on to say, is itself political:

Above all the polemical character determines the use of the word political regardless of whether the adversary is designated as nonpolitical (in the sense of harmless), or vice versa if one wants to disqualify or denounce him as political in order to portray oneself as nonpolitical (in the sense of purely scientific, purely moral, purely juristic, purely aesthetic, purely economic, or on the basis of similar purities) and thereby superior (1976, 31-32).

The political/non-political distinction is thus political. But it typically comes in the form of a claim that something is non-political by virtue of being "purely" something else. The political enemies of Protestantism were one of the sources of the modern notion of politics, and liked to distinguish religious from political considerations, implicitly denigrating the political as compromising and holding themselves in the higher category of religious. Indeed, "politique was the preferred term of censure deployed by Catholic Leaguers to besmirch all those who would abandon religious truth and seek accommodation with known heretics and proven schismatics" (Saunders 2006, 155). This is the politics of fanaticism, of which our world provides many examples. And as it happens, the history of science politics provides many more examples: scientists who believe that the speech of other people should be suppressed, or that people who have the wrong ideas should swing from the lampposts, as Karl Pearson thought, are depressingly common. Scientists have often been compared to priests in the course of this history, in accordance with the idea that they possess some special truth and ought to be respected and believed because of it. And some of them have behaved like priests, for example by demanding, recently, that free speech about global warming be suppressed if it does not fit with "the scientific consensus."

This sort of intervention belies any notion that the relation between experts and democracy is unproblematic and benign. They are dangerous to democracy in the same sense that the Catholic Church was, in its aggressive phases in the nineteenth and early twentieth century. The Taliban, the Mullahs in Iran, and so forth are dangers today for the same reason. But scientists don't in fact exercise such things as the power to suppress speech, as much as some of them might wish they did, so worrying about scientists in these terms sounds a bit crazy. This sense of craziness provides the motivation for Michael Schudson's essay in praise of experts and their contribution to democracy. For Schudson $(2006,492)$, experts are those people depicted by Walter Lippman eighty years ago, "who put aside their own interests and wishes when they examined the world," "people 
who cultivated the habit of discounting their own expectations," and were the saviours of democracy (which at the time was widely thought, because of the results of the use of mass intelligence testing by the Army, among other things, to be threatened by stupidity of the masses). Lippman thought that, as Schudson puts it, "If journalists had experts to rely on, they could inform the citizenry responsibly" (Schudson 2006, 492), and Schudson has similar views. He adds to this the sociological idea that scientists are professionals and that they would forfeit their professional existence if they strayed from the straight and narrow, giving various examples of economists who preferred to give the truth rather than succumb to political pressure $(2006,499-500)$. Experts, in short, are safe, because they police themselves - the same argument made almost sixty years ago by Robert Merton, who compared the social control of science to that of a police state.

So experts are not a threat to democracy because they discipline one another, they are disinterested, and, more important, are modest: they discount their expectations. Aside from this last point, this is a characterization of expertise completely devoid of epistemic content: nothing about the truth of what they say follows from any of it. Indeed, the Taliban and the authorities of the Catholic Church also do these things. One needs an additional story to get to truth-an epistemology that makes the creation of truth under these conditions more likely than in some other way. Then there is the problem of relevant truth. "Truth in a structured discipline" is something different from "truth as such" and different again from "truth as relevant to a particular set of political decisions made in the here and now under conditions of complexity, contingency, and time constraint." Schudson and the historical enthusiasts for expertise-who typically have gone with the full logic of the argument for expert knowledge and opted for expert rule in place of democracy, rather than as an adjunct to democracy (a question Schudson doesn't answer is "who needs a public sphere?")-generally ignore these differences and without argument conclude that deference to the representatives of a structured discipline is all the truth that democracy needs, or the best solution to democracy's need for truth.

The assumptions of this account need to be examined. In fact, the account of expertise is (almost) completely wrong, and the wrongness is a sign of the huge gap between the public sphere literature, which Schudson has in mind, and the sociology of science, not to mention epistemic considerations proper. If the expert can say "I have paid a high price for membership in the club of (economists, physicists, surgeons, engineers, etc.) and would lose my reputation and membership in the club if I lied to you," then he or she is saying something relevant to trust, though not directly relevant to truth: this is the same kind of reasoning and institutional practice that governs collective enforcement of trustestablishing practices in stock-brokering, law, psychiatry, and other professions. This might be thought to operate in science in relation to fraud, and in some extreme cases this is perhaps true (though actual high level cases, such as the David Baltimore affair, have turned out not to work in this way; actual cases of 
ruined careers are typically found among low-level contributors to large medical projects). But these examples, and the "discipline" of expertise itself, do not apply in any simple way to the domain of politically relevant truth. Consider Paul Ehrlich, whose every expert prediction in the policy-relevant domain proved to be wrong by a wide margin (a point gleefully made by his nemesis the economist Julian Simon). Not only was Ehrlich not expelled from the community of biologists, he was treated as a noble martyr to the cause of truth merely for suffering the indignity of having his claims questioned by non-biologists. In fact, ostracism is more likely to result from challenging conventional opinions in the community than from being wrong over and over again but conforming with the community. But there is more. One of the best established findings of oldfashioned sociology of science was that making mistakes has virtually no career costs.

But there is a bigger issue. Professional communities are routinely, if not invariably, wrong. The inductive hypothesis in the philosophy of science, to the effect that our present scientific views can expect to be proven wrong because all past scientific views have been proven wrong, applies even more strongly to expert opinion, which seems to obey the pendular laws of fashion more often than the laws of scientific progress. To read an expert advice book of the early part of the last century is usually an exercise in the realm of the comic. Not infrequently, one sees the origins of the old wives' tales believed by one's grandparents. Yet, these were often based on data and reasoning as good as or better than the data and reasoning employed today. So scepticism about the truth of expert opinion is well warranted apart from questions of motive. And one reason they are so spectacularly wrong is precisely that the careers of experts tend to be bound up in a disciplining process that makes errors both inevitable and consensual, by punishing those who don't go along.

And there is an even more important issue. Experts typically make their reputations as real scientists, economists, or whatever. And they typically are careful to say nothing that conflicts with the rules of the game in their fields. Experts whose thing it is to speak for their field, and who are also professional apostates, are nonexistent. This is a role for the orthodox. But this does not mean that their pronouncements on policy conform to well-defined rules of the game. Far from it. Policy issues, including such policy issues as global warming, are partly based on facts, partly based on uncertain claims, on beliefs about human conduct and on other things, such as ideas about what is and is not natural about weather fluctuation, that are based on complex and uncertain inferences from data, or on guesses. They are epistemically different from what is ordinarily understood as science.

Moreover, experts routinely, contra Schudson, overreach, as the case of Paul Ehrlich shows. Is this the issue? Should they be more modest, as Lippman fantasized they were? Shouldn't "experts" just recuse themselves when they 
don't really have the facts to warrant a policy? The answer is not so simple. Consider an area in which expert claims have been made for decades, and invariably turned out to be not only false but deleterious to the objects of the expertise: development economics. Should development economists just shut up? They do know some things. But, realistically, they don't know how to produce vibrant economies in the Third World or lead millions out of poverty under the actual political and cultural conditions of impoverished nations. Does this mean they should they stop trying as experts to formulate policies and policy ideas? Probably not. Experts have no special expertise or meta-expertise that would allow them to know when their knowledge is partial and inadequate for particular purposes: this is something they learn by applying it. This is perhaps a domain in which the urgency is such that trying on the basis of very limited understanding is the only option. And urgency, or perceived urgency, is probably a reason biologists give Paul Ehrlich an ethical pass on his long list of false predictions.

What is a citizen to do in the face of a world of expert claims, many of which are dubious? There is a developing literature on the quality of public discourse that identifies the discussion of the decision to invade Iraq in the administration of George W. Bush as a failure. But there was no lack of discussion. C-SPAN ran an all night session of the United States Congress in which the issues were thoroughly aired. The public accepted the opinions of experts and an expert community. The experts were wrong despite producing all the right cues, establishing a consensus, and otherwise making themselves credible. Can the public be faulted for accepting their expertise? The question is a genuinely difficult one, and speaks to the whole question of democracy's capacity to deal with expert claims; a capacity tested equally by the case of the many claims of climate science.

In such cases, and indeed in all real world cases of any interest, meekly accepting the advice of experts is not good enough-it is bad public epistemology and an abdication of political responsibility. Simply delegating such questions to experts is, in any case, typically not possible. Experts may have opinions about policy questions, but these opinions don't have the authority of "science" in the sense intended-namely that they are part of something like a textbook consensus. Nothing in textbook science or for that matter economics is sufficient to settle any serious policy question. It is knowledge, but it is knowledge that needs to be put together with other people's knowledge to add up to a rational and epistemically sound decision. This is best understood, I will suggest in the next section, epistemically: as a problem in the aggregation of knowledge.

The Aggregation Problem: How to think epistemically about expertise and politics

The problems that characteristically involve expertise have the following properties: decisions need to be made, for example about a policy; knowledge is "distributed," usually among many people and-this is crucial to what follows- 
unequally so; decision makers, whether this means judges, the public, representative bodies, administrators, or commissions, must rely on or judge claims which they cannot epistemically fully own, that is to say other people's knowledge which they can only get second hand and can't judge as a peer. And there are political implications in Schmitt's sense-some faction loses, is devalued, etc. If neither simple "expert scepticism" is the solution to this generic problem, nor affirming the importance and value to democracy of experts and encouraging deference to them, is the solution, what is? The issue is this: we are talking about comparatives here, and the comparison cases are unstated and untheorized. The contrast in this case should not be "doing without expert knowledge claims entirely," but something else. The question is "what else?"

I suggest that we see the problem of expertise, and the reliance on experts by democratic politics, as itself a solution, among other solutions, to a genuine epistemic problem, a problem of the aggregation of distributed knowledge for the purposes of making decisions: call this subject "political epistemology." Policy and politics happen in real time and in a world, as Schmitt himself famously said, in which a bad decision is often better than no decision at all. This is crucial to understanding the appeal of expert claims: in many cases people want guidance to solve problems that they consider important, and will embrace any credible expert who claims to have a solution, or even some facts relevant to the solution. But policy questions and the kinds of knowledge relevant to them is never a matter of "facts" of the sort that experts possess. The policy must always go beyond the facts, and is usually a complex mixture of "fact" and things that are the subject of considerable uncertainty. Among them are considerations about implementation, who is affected and how, what their wishes and preferences are, and practicalities of other kinds. Experts who know the facts in the narrow sense may feel that they have a special qualification for pronouncing on the things in this grey area, which relate to the facts in the narrow sense, but which are not, properly, the same sorts of epistemic objects. The long history of atomic scientists attempting to intervene in the weapons policies of their countries is an example of this. The truth of expert claims about complex mixtures of this kind is likely to be determined only in retrospect, so "truth in the long-run," which science purports to provide, is not a useful concept for distinguishing them in the here and now. The claims of science are part of what needs to be considered by decision-makers. But prudence broadly construed, and the prudent weighing and judging of expert claims, is the standard.

So what prudent alternatives are there to reliance on experts by the public? What is the comparison class? What are the other solutions to the problem of the aggregation of knowledge? I list a few below, with some references to my own attempts and those of others to make sense of this murky subject. In each of these cases my strategy is to "ask the knowledge question" about a particular institutional case. 
1) Markets. For some problems, such as the aggregation of knowledge about individual preferences, the market is the best known source of information. What will people pay? There is no good way to find this out besides putting products in a market and watching them choose by paying particular prices and balancing these choices against others.

2) Families. This is Kitcher's model, and it is a solution to the problem of trust and conflict of interest and perspective between experts and the public. The idea is that the expert acts in a paternalistic (or maternalistic) way toward that which is theirs, including both their special knowledge and their family, and respects and accepts the concerns of the other members of the family. Knowledge is mostly, but not entirely, in the hands of the expert, and so is learning (cf. Turner 2003).

3) Stakeholder models. This is another approach to the problem of melding knowledge and interests. If we attempt to make the people with both interests in and knowledge about something sit down and negotiate a consensual solution, we avoid the problem of inadvertently goring someone's ox, or of having their knowledge ignored. Since decisions are consensual, no one is forced to yield on the things they regard as most serious-either interests or beliefs-but they must sacrifice something less salient to them to achieve consensus, and make an ongoing choice, involving their knowledge, about the value of the consensual goal. Since these negotiations are typically secret or semi-secret, there is little learning, though the participants may learn a great deal, and have an incentive to learn, about matters involving their interests and beliefs, and those of other participants (cf. Turner 2004).

4) Representative democracy. It may seem odd to think of this as a means of knowledge aggregation, but of course it is. Expert rule is usually understood as a rival to and improvement on representative democracy, with reliance on experts by democracy an improvement that avoids the bad normative implications of expert rule, though expert rule is something that many thinkers, such as J. D. Bernal and Karl Pearson, preferred. But there are some epistemic benefits to liberal democracy. Like the stakeholder model, legislative politics forces representatives and those they represent to choose: no consensus is required, but voting procedures produce decisions by compromise and horse-trading, the horses being interests and beliefs which are valued in the political market. 
In the U.S., representatives know and look out for their constituents' interests; in Europe, interests are mediated through parties. Legislatures have long memories of their own precedents, and learn from them (Turner 2007c).

5) Self-regulating "expert responsibility" models. Consider the following problems of decision-making in the face of distributed knowledge: NASA's decisions to launch, the dropping of the A-bomb, Commissions reviewing policy issues and producing White Papers. In the case of NASA, there were approximately five thousand critical flight-threatening issues in every launch. No one could even list, much less make judgments about, all these technical issues, each of which involved significant uncertainties. Those best able to judge how serious the problem was, i.e. the engineers in each relevant group, were given the responsibility to raise issues at a higher level, and held accountable. Surprisingly, they guessed wrong in ways that produced catastrophes only twice (cf. Turner 2005). The A-bomb decision involved a pyramid of technical committees tasked with specific issues, leading to a technical committee which weighed options. Each committee had limited scope and responsibility. The final technical committee expected, by historical precedent, that their decision would be examined by Congress if something went wrong-as the alternative choice, the invasion of Japan could very easily have gone wrong (Turner 2007c).

6) Bureaucracy. This combines expertise, especially in the form of examinations and in-house knowledge, with elaborate consensus favouring career structures. Subject to what we may call, after Isaiah Berlin, "hedgehog error." Bureaucracies know one big thing, but they are often wrong, and there are few corrective feedback mechanisms, usually little transparency, and an internalization of knowledge or closure to the outside world, which produces knowledge claims that typically are not directly relevant to the internal knowledge production processes of the bureaucracy (cf. Turner 2004; 2007c).

7) Direct expert commissions in a market like-atmosphere of conflicting or different expert claims. John Snow's demonstration of his correct understanding of the mechanism of cholera was a result of this kind of competition-the alternative was the wrong view of the British health bureaucracy and of the medical expert consensus (Turner 
1997; 2004).

8) Artificially created public/expert forums. These are mostly legitimation devices rather than means of aggregating knowledge, but through dialogue, concerns, beliefs, and preferences of the non-expert participants, knowledge that is typically not readily available in any other way.

9) Mechanical aggregation procedures. The model is guessing the number of beans in a jar. This approach avoids process problems, since the guesses are mathematically combined, for example, by taking the mean. It also minimizes interests, and therefore interest-related bias. But there is no learning, collectively or individually, and as a method it does not apply when there are issues which are not more or less quantifiable, for example, where there are conceptual incommensurabilities.

10) Deference to experts speaking as a community. Professional bodies, for example physicians, often produce collective advice, which relies on "professional" standards and control. It is subject to hedgehog error or group-think, as well as bias when professional selection or professional interests produce patterns of special interest. Learning depends on internal collective processes of consensus formation, which may be problematic in various ways.

11) Oracles. One might regard this as a joke. But flipping coins is a decision-procedure with some good properties, notably lack of bias. Weber regarded the specific form of the use of oracles by the ancient Jews as one of the keys to the origins of Western rationalism. Why? Because by making the answers come in a yes/no form, they forced the users to carefully construct and thus rationalize the questions (cf. Turner 2007b). One might even say that this was a collective, or expert, employment of knowledge, as it involved religious institutions. There is no learning, except with respect to the posing of questions.

12) Parties as Expert Bodies. The experiment with Communism managed to combine the epistemic traits of bureaucracies with political power, making truth and authority both a matter of the party line. This form elevates group-think and expert consensus, which is nominally independent of the state bureaucracy, into the core governing principles of the state (Turner 2006). Learning is done in conformity with party doctrine, and thus aspires to coherence at the cost of other epistemic values. 
13) Science. There is a sense in which "science" also aggregates knowledge, but not in the same sense. Science involves many decisions, to publish papers, to award grants, to give degrees, prizes, and so forth (Turner 2002). These are decisions only indirectly related to "truth" as such. The normal mode of "aggregation" is this: scientists speak "for science" as representatives, and this is accepted if it is not challenged. When scientists are forced to make epistemic decisions collectively, however, and to produce a consensus artificially, trouble-in the form of disagreement over what the "consensus" is-usually follows, as it has, for example, in relation to the consensus assertions of the Intergovernmental Panel on Climate Change.

One might extend this list indefinitely, and consider many other puzzling examples of expertise and knowledge aggregated into a whole that can serve as the basis for state action or public discussion. There is, for example, the knowledge of the dead of generations past, black-boxed into the technology and procedures we take for granted. But the list is sufficient to make the point that the democracy-expert relation is more complex than a matter of accepting the model of deference to experts or rejecting it. Rejecting it is usually understood as a matter of embracing an alternative-populism, or as Ségolène Royal put it, the expertise of the people, which she meant to contrast to that of the administrative class. Notice that this is not an alternative on this list, and for good reason. The reason is parallel to the reason "democratic legitimacy" is not on Weber's celebrated list of types of legitimacy. By itself, "democracy" is not a form of legitimation: it requires additional legitimating beliefs, such as the belief in the charisma or sacredness of the popular will, or in the procedures of democratic lawmaking. Similarly, popular expertise, participation, etc. are not in themselves methods of aggregating knowledge. Rather, they require some method to put all the knowledge in question into a means of decision-making. Royal had in mind the demonstrations against changes in youth employment policy, which is to say the aggregated wisdom of the mob, which bureaucrats were to respond to as a surrogate for a public opinion poll, a form, though a crude one, of aggregating knowledge.

At the end of the Enlightenment, Condorcet grasped with wonderful clarity that epistemic equality between citizens and scientists was an impossibility, and also understood that this had the effect of undermining the ideal of democratic rule. His immediate successors, Saint-Simon and Comte, took this a step further and renounced the ideal in favour of expert rule. This episode has been conveniently forgotten by today's enthusiasts for democratic deliberation and the public sphere (cf. Turner 2007a). What the democratic deliberation and 
public spheres literatures have studiously avoided grasping is the role of knowledge, as opposed to interests and identity politics, in the public sphere. But the reason is not that the problem has disappeared in the "Knowledge Society." It is rather that it has become so complex and pervasive that it is no longer visible as the option of expert rule. Our problem is to make it visible again. Revealing how knowledge actually flows, how it actually aggregates, and how aggregation fails, is a contribution that expertise studies can make to the public sphere and democratic deliberation literatures- a contribution that has the potential for transforming these literatures in a more realistic direction.

\author{
STEPHEN TURNER \\ Department of Philosophy \\ University of South Florida \\ Tampa, FL 33620 \\ turner@shell.cas.usf.edu
}

\title{
References
}

Kitcher, Philip. 2001. Science, truth and democracy. Oxford: Oxford University Press.

Lippman, Walter. 1920. Liberty and the news. New York: Harcourt, Brace and Hone.

Lippman, Walter. 1922. Public opinion. New York: Macmillan.

Saunders, David. 2006. The judicial persona in historical context: The case of Matthew Hale. In The philosopher in early modern Europe: The nature of a contested identity, ed. Conal Condren, Stephen Gaukroger and lan Hunter, 140-159. Cambridge: Cambridge University Press.

Schmitt, Carl. 1976. The concept of the political, trans. George Schwab. New Brunswick, NJ: Rutgers University Press.

Schudson, Michael. 2006. The trouble with experts - and why democracies need them. Theory and Society 35: 491-506.

Turner, Stephen. 1997. "Net effects": A short history. In Causality in crisis, ed. Vaughn McKim and Stephen Turner, 23-45. Notre Dame, IN: University of Notre Dame Press.

Turner, Stephen. 2001. What is the problem with experts? Social Studies of Science 31(1): 123-49.

Turner, Stephen. 2002. Scientists as agents. In Science bought and sold, ed. Philip Mirowski and Miriam Sent, 362-84. Chicago: University of Chicago Press.

Turner, Stephen. 2003. The third science war. Review of Who rules in science: An opinionated guide to the wars by James R. Brown, and Science, truth and democracy by Philip Kitcher. Social Studies of Science 33(4): 581-611.

Turner, Stephen. 2004. Quasi-science and the State. In Governing science in comparative perspective, ed. Nico Stehr, 241-268. New Brunswick, NJ: 
Transaction.

Turner, Stephen. 2005. Expertise and political responsibility: The Columbia shuttle catastrophe. In Democratization of expertise? Exploring novel forms of scientific advice in political decision-making, ed. Sabine Maasen and Peter Weingart, 101-21. Dordrecht: Kluwer.

Turner, Stephen. 2006. Was Real Existing Socialism a Premature Form of the Rule of Experts? In Democracy and civil society east of the Elbe, ed. Sven Eliaeson, 248-61. London: Routledge.

Turner, Stephen. 2007a. The social study of science before Kuhn. In The Handbook of Science and Technology Studies, $3^{\text {rd }}$ ed., ed. Edward J. Hackett, Olga Amsterdamska, Michael Lynch and Judy Wajcman, 33-62. Cambridge, MA: MIT Press.

Turner, Stephen. 2007b (forthcoming). Blind spot? Weber's concept of expertise and the perplexing case of China. In Max Weber matters, ed. David Chalcraft. Aldershot: Ashgate.

Turner, Stephen. 2007c (forthcoming). Balancing expert power: Two models for the future of politics. In Knowledge and democracy: Is liberty a daughter of knowledge, ed. Nico Stehr. New Brunswick, NJ: Transaction. 